\title{
5 Poems
}

\section{Vanessa Ovalle, University of Southern California in Los Angeles}

Vanessa Ovalle is a Latina poet of Mexican descent. She grew up in Southern California speaking Spanglish, a combination of English and Spanish. This linguistic and cultural mixing would lead her to explore questions of language, translation and cultural authenticity in her poetry and academic study. As a senior at Cornell University Vanessa completed an undergraduate senior thesis entitled ' $\mathrm{C}$ - in Spanish for Bilinguals,' which included both poetry composition and critical analysis. Currently she is a $\mathrm{PhD}$ student in Comparative Studies in Literature and Culture at the University of Southern California in Los Angeles. 


\section{Idealogue}

so easy to write yourself in a corner she did that my roommate on Jackie upstairs' birthday, her letters condensing like carnation of ink feathers in the corner of a hallmark card "I can't write anymore!"

_ "stuck in a corner."

roommate room / mate two o's / two m's mirroring handclap Manhattan and Puerto Rico California and Mexico words writing us in corners palomas strung out on the tips of hallways, and what if you / your

ideologue are / is a contrafactual? doubt it could fly if it wasn't "real" if I was / if I were you: an idea.

lets live in this subjunctive, roommates, you the if that will surely be true 
2

\section{Murrieta}

Portrait of a suburban town in Southern California

Wachale, you're in Joaquin's land.

His etch-a-sketch retrato hangs

lost, so admire the dolly shot

of our sim world: the Applebees

Fridays, Macaroni Grill with Maltese

pooches in purses licking the soft-rot

from sugar town brows beneath blondie bangs.

Hot Springs brewed tupperwared ladies

are riding sails on Mercedes

to Westfield malls. It's burning May;

food scraps fluxing in radioactive decay

are mixed in car-seats and cat sand.

The cradle of mierda in Joaquin's fangs

cakes murmurs on a Teflon pot. 
3

\title{
DÉCALAGE
}

\author{
the process of absence \\ a "gap" "delay" "time/jet/leg-lag" \\ the attempt try rinse repeat \\ to kiss a diaspora \\ that scatters guasóna \\ rogona across burnt lips, nose, and eyes like rain drops \\ count the spiders in a field of yerbas lost besos \\ that seek to master mist falling from a tumbling \\ sky hold your décalage and nurture \\ the untranslatable loneliness in identity \\ that becomes soledad identidad when you \\ hold it
}

she asked me if I wanted

habichuelas so I went hungry waiting for my frijoles

she offered me a colcha

so I went cold hoping for a spare cobija

bad impressions

and we're not so the same. but not so different, right?

I don't know anyone else who mows zacate anyway,

at least not in nueba yol.

I don't recognize your laugh, your dancing

exotic seductive but untranslatable

curly hair that coils like christmas wrapping

while mine bounces wild, irregular

I suppose it won't matter after

we've finished straightening for each other,

sharing the iron,

articulation that feeds our hambre

for unidad and individuality, comunidad but

unicos rinsing, repeating

rogona guasóna $i$ !

diaspora laughing 
4

\section{Bardem's Equilibrium}

after the film "Calle Mayor"

One over zero, that's how alone the blanco

of the broma burns when it gets to nothing and you flick the cigarette to Palencia cobblestones, twist leather sole until ashes to ashes. There is no shot of the novia wallowing down Calle Mayor, but this close-up is where everything happens. The cathedral bells ring ritual into breakfast plates of obstructed takes behind chandeliers. What happens when we all suffer the aburrimiento colectivo? Are we prone to play nuclear pranks for fun or does national security will it to be so? Enough said. Betsy Blair didn't have a say in the matter, she was the butt. Dubbed to perfection without a moan of protest to her resume. Not even a risa, ni siquiera a Spanish one. A clay pigeon stares out into the rain along Calle Mayor, her wedding gown hangs flaccid on the hanger behind her. Fin.

But it's not over, because Juan is still missing and Isabel and that whore Toña, Dora Doll, will be waiting two over zero forever. Señora Dónde Vas makes nothing but a desperate cameo in the train station, and I'm sure you're all wondering -who is this woman and where can I meet her?

I'm pretty sure we're family so maybe for some big milestone type thing, the piano tuner will be adjusting and everything will seem too good to be you. The pitch undulates another right from wrong. Later, Frederico will burst through the stage right double doors [take \# three over zero] the shine on your ballroom floor turns to glare, hands positioned on the small of your back, he will dip you. Enter: equilibrio. Enter: ¿Sra. Dónde Vas? 
5

\section{native on canvas}

physically outside and of

the place serpents of gold

charm us

scaly belts tempt lips to

breasts the primitivism

en vogue where a woman finds

herself, coal sparks

at attention, swallowing her

eyes. that fringe

I was born near a weeping willow is no

reason to devote my

art to this rather limited liaison

exoticism of gender of place

legs with stubble and six fingered

dreams that beg me to forget

my burnt skin.

my guts

write something in spanish: natural

and kick kick trip at the curb

until you fall

bust your lip and

bleed spanish,english, french,color the

local curses and prayers

ladders for flutes

the rehearsals that life imposes

native dreams, naturally

a delusion

to move

culture with nature

desire

for culture

and symmetry

forgetting

their wild and earth breathing

wombs: the presence of her black

body, invisible 